\title{
IMPLEMENTATION \& PERFORMANCE ANALYSIS OF BIDIRECTIONAL FSO CHANNEL IN HYBRID TDM/WDM GIGABIT PASSIVE OPTICAL NETWORK
}

\author{
Kehkashan A. Memon \\ Department of Electronics, Mehran U.E.T Jamshoro (Pakistan) \\ E-mail: kehkashan@faculty.muet.edu.pk
}

A.W. Umrani

Department of Telecommunication, Mehran U.E.T Jamshoro (Pakistan) E-mail: waheed.umrani@faculty.muet.edu.pk

M.A. Unar

Department of Computer Systems, Mehran U.E.T Jamshoro (Pakistan)

E-mail: mukhtiar.unar@faculty.muet.edu.pk

Wajiha Shah

Department of Electronics, Mehran U.E.T Jamshoro (Pakistan) E-mail: chairman.es@admin.muet.edu.pk

Recepción: 05/03/2019 Aceptación: 27/03/2019 Publicación: 17/05/2019

\section{Gitación sugerida:}

Memon, K. A., Umrani, A. W., Unar, M. A. y Shah, W. (2019). Implementation \& Performance Analysis of Bidirectional FSO channel in Hybrid TDM/WDM Gigabit Passive Optical Network. 3C Tecnología. Glosas de innovación aplicadas a la pyme. Edición Especial, Mayo 2019, pp. 166-181. doi: http://dx.doi.org/10.17993/3ctecno.2019. specialissue2.166-181

\section{Suggested citation:}

Memon, K. A., Umrani, A. W., Unar, M. A. \& Shah, W. (2019). Implementation \& Performance Analysis of Bidirectional FSO channel in Hybrid TDM/WDM Gigabit Passive Optical Network. 3C Tecnología. Glosas de innovación aplicadas a la pyme. Special Issue, May 2019, pp. 166-181. doi: http://dx.doi.org/10.17993/3ctecno.2019. specialissue2.166-181 


\section{ABSTRACT}

In this paper, experimental work is performed on hybrid TDM/WDM Gigabit Passive Optical Network by replacing the last mile optical fiber with Free Space Optical channel. A Hybrid GPON system is a more intelligent choice of today's passive optical networks because it provides benefits of both TDM as well as WDM technologies at Giga b/s. And the use of Free Space Optical channel will bring the last mile network to its peak performance. This paper demonstrates the performance of hybrid TDM/WDM GPON system utilizing FSO channel in terms of Quality of factor and Bit error rate along with eye diagrams. This system is a full bidirectional system working on $2.5 \mathrm{~Gb} / \mathrm{s}$ downstream and $1.244 \mathrm{~Gb} / \mathrm{s}$ upstream transmission. The system is using varying lengths of FSO channel to analyze the GPON network performance. The simulation results using Optisystem v. 15 verify the fully functional bidirectional transmission of FSO link between OLT and ONU and achieve BER of the order of $10^{-16}$ and $10^{-12}$ at a distance of $100 \mathrm{~m}$ for both upstream and downstream respectively.

\section{KEYWORDS}

Passive Optical Networks, Hybrid TDM/WDM GPON, Free Space Optics, Optisystem. 


\section{INTRODUCTION}

The growth of sophisticated and intelligent devices which brings the need of virtually always stay connected with anything and everything we can think of is creating a demand of high data rates which could support the triple play. So there is a massive deployment of FTTH (Fiber - To-The -Home) to serve more number of users with increased bandwidth (Kaur, Kaur \& Singh, 2017). Passive Optical Network (PON) architecture is adopted across the globe in order to provide higher bandwidth support (Ahsan, Lee, Newaz \& Asif, 2011). More specifically, the Gigabit PON or GPON provide a powerful point--to multipoint solution to satisfy the increasing capacity demand in the access part of the communication infrastructure, between service provider central office $(\mathrm{CO})$ and a number of Optical Network Units (ONUs) at the consumer premises (Skubic, Chen, Ahmed, Wosinska \& Mukherjee, 2009).The hybrid GPON is a hybrid passive optical network, where WDM-GPON and TDM-GPON are integrated into a single passive optical network (Liu, Zhang \& Li, 2011). Hybrid TDM/ WDM means for downstream we are using wavelength division multiplexing only and in the upstream we are using Wavelength Division along with Time Division so that multiple Optical Network Units (ONUs) which are using the same wavelength do not send overlapping data. At the user end the deployment of Free Space Optical (FSO) channel instead of Optical fiber is the main focus of this work. FSO can be considered as an alternative to the Optical Fiber cable or $\mathrm{RF} /$ Microwave systems especially when the physical connections are impractical due to several considerations and it has become the ideal choice for the access technology (Memon, Umrani, Unar, Shah \& Chowdhry, 2018).

Pla (2011) has worked on the TDM/WDM GPON utilizing a 2.5Gbps rate for downstream and $1.244 \mathrm{GBps}$ rate for upstream communication. The author has taken five areas and the system is completely optical fiber based. The main bidirectional optical fiber connecting the Optical Line Terminal (OLT) to Optical Distribution Network (ODN) is of $5 \mathrm{Km}$ in length. At the access network side the lengths of bidirectional optical fiber in each area are different depending upon the requirements of that area. In this work, we are implementing the FSO 
channel at the ODN/ONU side. The main backbone fiber cable has a length of $50 \mathrm{Km}$. and two different areas are simulated namely hospital block and building block. Each block has an FSO channel for upstream and downstream. The FSO channel length is one of the major issues which can impact the performance of the system. So the objective of this work is to take five different ranges, from $50 \mathrm{~m}$ to $250 \mathrm{~m}$ and analyze the system performance. Considering the tropical environment such as of Pakistan, this system is going to provide performance in terms of $\mathrm{Q}$ factor and BER along with eye diagrams.

The remaining sections are organized as follows. In section II system architecture is discussed highlighting separately the downstream and upstream components, its communication system and parameters. Section III discusses the experimental results and gives the performance analysis in the form of eye diagrams, Quality of factor and BER with respect to the multiple ranges of FSO channel. Section IV concludes the paper. This is followed by section V and VI for acknowledgement and references.

\section{SYSTEM ARCHITECTURE}

Figure 1 shows the complete system design of a hybrid TDM/WDM GPON. For understanding, first the downstream connectivity is explained which is from OLT to ONUs and then upstream connectivity is explained $\mathrm{i}^{-} \mathrm{e}$ from ONUs to OLT. As seen in Figure 1 the system comprises of three main sections, first is OLT, followed by backbone channel and finally the Access network. The bit rate used in this system is $2.5 \mathrm{Gbps}$. The system is based on two areas namely Hospital block and Building block. Therefore, two wavelengths will be used.

\subsection{DOWNSTREAM ARCHITECTURE}

Referring to Figure 1, the Optical Line Terminal (OLT) consist of WDM Transmitter that can provide multiple wavelengths. These wavelengths are multiplexed by WDM multiplexer. We are using 2 different wavelengths $\lambda 1=$ $1450 \mathrm{~nm}$ and $\lambda 2=1470 \mathrm{~nm}$ with frequency spacing of $20 \mathrm{~nm}$. The extinction 
ratio is set on $10 \mathrm{~dB}$. WDM Mux is required to combine the wavelengths to be transmitted on a single fiber. The WDM mux has a bandwidth of $80 \mathrm{~nm}$ with an insertion loss of $2 \mathrm{~dB}$. To ensure a good quality signal transmission an optical amplifier with a $15 \mathrm{~dB}$ gain is also used. A Bidirectional circulator is used to transmit downstream data to the ONUs and to receive upstream traffic from the ONUs. The downstream optical signal is passed through the main backbone channel which is a bidirectional optical fiber having a length of $50 \mathrm{Km}$. Table 1 gives the parameters of bidirectional optical fiber.

Next comes the access network / (ODN) which comprises of a splitter and two units namely hospital and buildings blocks. The first branch of the splitter is connected to hospital block and the second is connected with the building block.

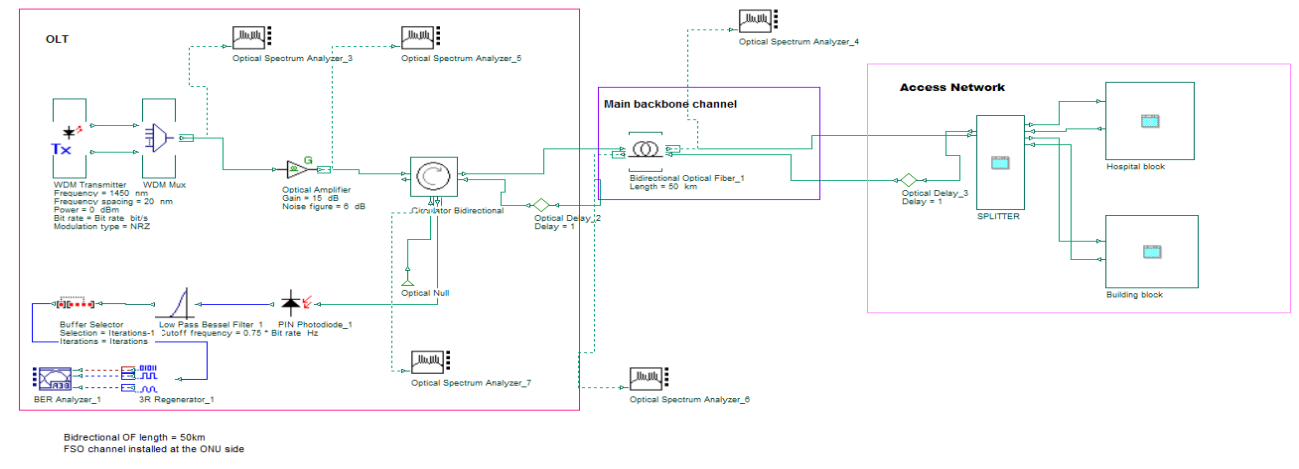

Figure 1. TDM/WDM GPON complete design.

Table 1. Parameters of Bidirectional Optical Fiber.

\begin{tabular}{|c|c|}
\hline Parameters & Value \\
\hline Reference wavelength & $1450 \mathrm{~nm}$ \\
\hline Length & $50 \mathrm{~km}$ \\
\hline Attenuation & $0.2 \mathrm{~dB} / \mathrm{km}$ \\
\hline Dispersion & $16.75 \mathrm{ps} / \mathrm{nm} / \mathrm{km}$ \\
\hline Dispersion slope & $0.075 \mathrm{ps} / \mathrm{nm}^{2} / \mathrm{km}$ \\
\hline Effective area & $80 \mathrm{um}^{2}$ \\
\hline
\end{tabular}

Figure 2 shows the hospital block, which contains the FSO channel for downstream. The FSO channel parameters are given in Table 2. The length of the FSO varies from $50 \mathrm{~m}$ to $250 \mathrm{~m}$. This channel is connected to the ONU of hospital block (figure 3) where downstream data is detected by PIN photodetector which will transform the optical signal into electrical. This output is connected to 
a Low pass Bessel filter and finally to a $3 \mathrm{R}$ generator which is connected to the BER analyzer for detecting the performance in terms of $Q$ factor, eye diagram etc. The other part of ONU is discussed in upstream architecture.

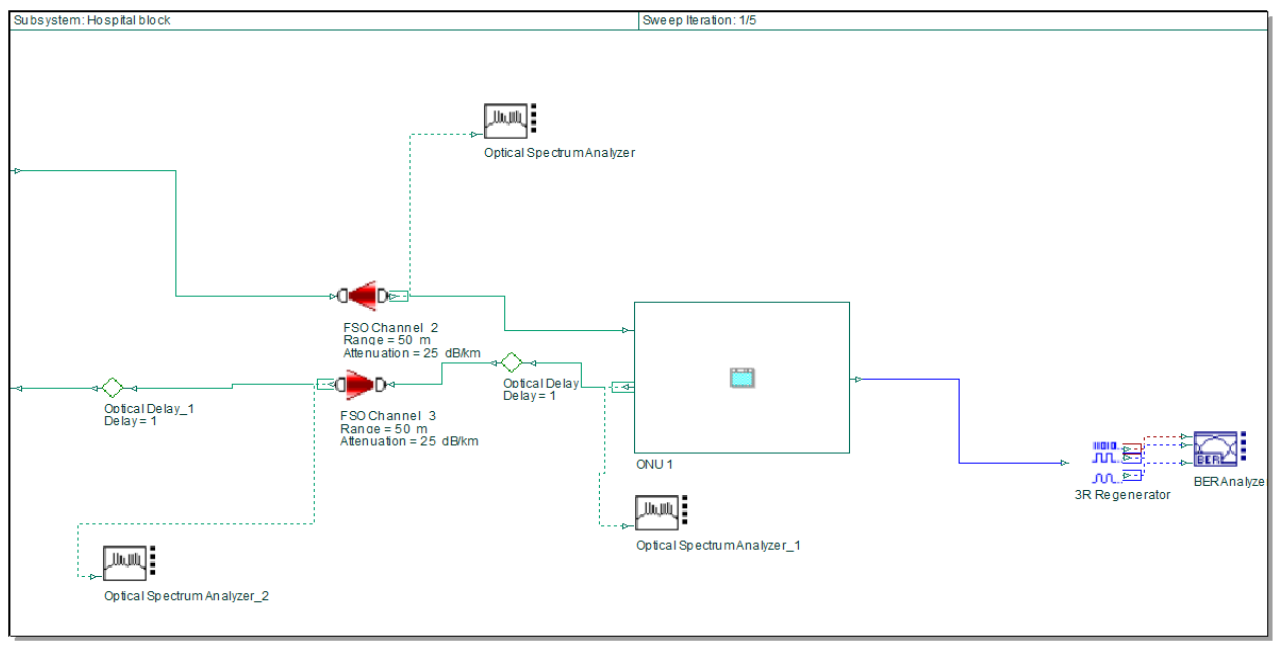

Figure 2. Hospital Block.

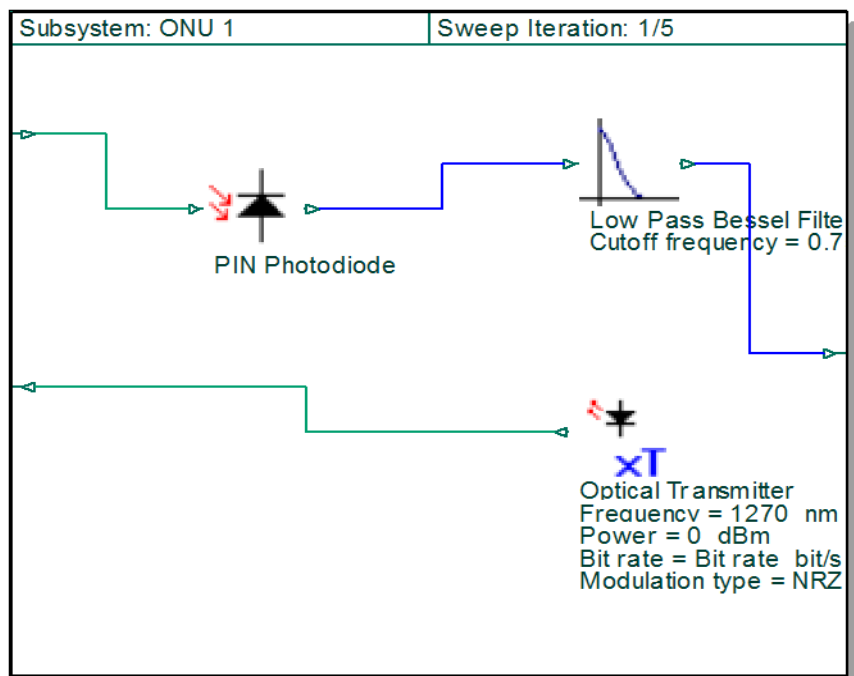

Figure 3. ONU for hospital block.

Table 2. FSO channel parameters.

\begin{tabular}{|c|c|}
\hline Parameter & Value \\
\hline Range & 50 to $250 \mathrm{~m}$ \\
\hline Attenuation & $25 \mathrm{~dB} / \mathrm{km}$ \\
\hline Transmitter aperture diameter & $5 \mathrm{~cm}$ \\
\hline
\end{tabular}




\begin{tabular}{|c|c|}
\hline Parameter & Value \\
\hline Beam divergence & $2 \mathrm{mrad}$ \\
\hline Receiver aperture diameter & $20 \mathrm{~cm}$ \\
\hline
\end{tabular}

The second branch of the splitter is connected to Building block which is shown in Figure 4. This block contains two sections of buildings and both will receive $\lambda 2=1470 \mathrm{~nm}$.

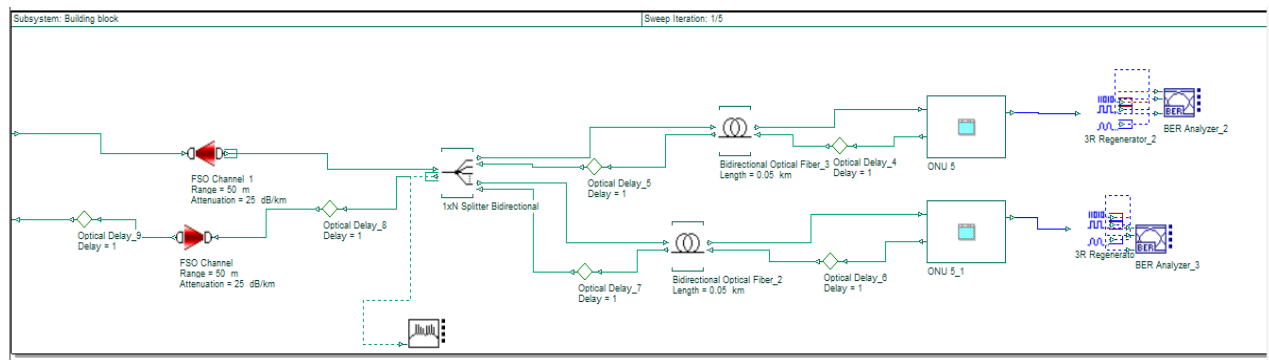

Figure 4. Building block.

In Figure 5 it is shown that FSO channel is used for downstream as well as for upstream, and its output is again connected to a 1:2 splitter because there are two ONUs or two sections of the building each receiving the same wavelength in the downstream. Inside the building unit, there is again a $50 \mathrm{~m}$ bidirectional optical fiber which is used control both upstream and downstream data from both ONUs. The ONU structure is shown in Figure 5.

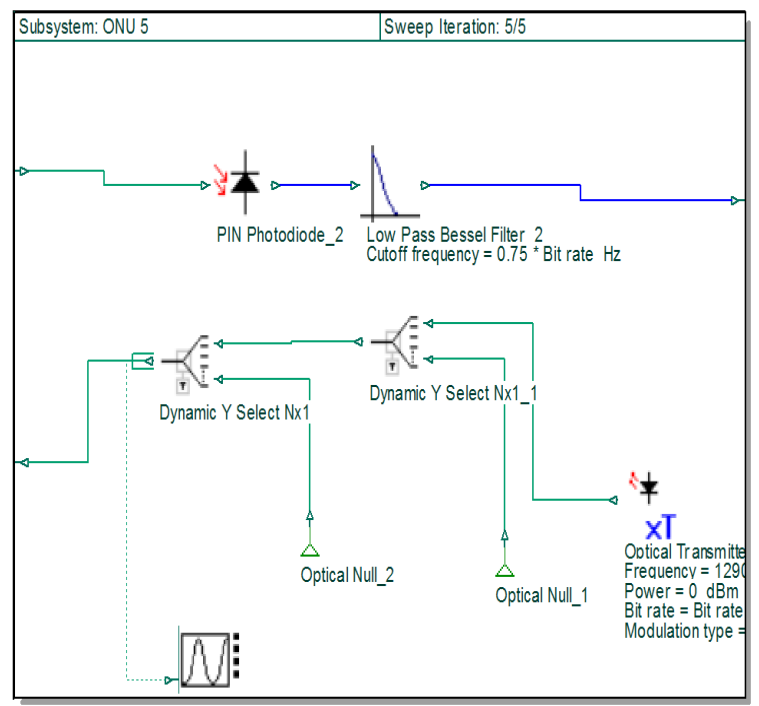

Figure 5. ONU for building block. 
Figure 5 also contains the same detection mechanism i-e PIN photodetector which is connected to loss pass Bessel filter that is connected to the $3 \mathrm{R}$ generator and BER analyzer. The other part is upstream which is discussed in the upstream architecture.

\subsection{UPSTREAM ARCHITECTURE}

In the upstream direction, the optical signal will travel from each end user (ONU) to the OLT, Pla (2011). So now the OLT is the receiver and each ONU will work as a transmitter. Refer to Figure 3 for ONU of the hospital block. Here there is only one ONU, the optical transmitter will transmit at $1270 \mathrm{~nm}$ with the power of $0 \mathrm{~dB}$. This data will be sent to the OLT via FSO channel having the same parameters as shown in Table 2. The output of this FSO is connected to the splitter which is now working as a multiplexer. This splitter output is connected to the backbone bidirectional optical fiber which will send the upstream data to the OLT. In the OLT the circulator is bidirectional hence the upstream data will be received separately in the OLT via PIN photodetector, LP filter, buffer selector, 3R generator and finally BER analyzer.

In Figure 4 there are two sections for building block hence both will share the same wavelength $1290 \mathrm{~nm}$. In this case, we can utilize the benefit of TDMA by allotting a specific time slot to each ONU so that the data don't get overlapped. Therefore as shown in Figure 5 the ONU of building block contains an optical transmitter whose output is connected to dynamic y select which will allow the ONU to send its data in its specific time duration. The output of the dynamic y select is connected to other devices which are already explained and are shown in Figure 4.

\section{EXPERIMENTAL RESULTS}

With the above explanation of complete system architecture, the experimental results are discussed here. The results are in shape of Eye diagrams, Max. Q factor, Min. BER with respect to the range of FSO channel. Therefore in this section, we determine the feasibility of the FSO channel in the last mile network. 


\subsection{DOWNSTREAM PERFORMANCE ANALYSIS}

In the case of ONU for hospital block, Figure 6 shows the eye diagram results when the FSO channel range is $50 \mathrm{~m}$ and $100 \mathrm{~m}$. After $100 \mathrm{~m}$ the eye diagram degrades significantly. Table 3 gives the BER analyzer values for hospital block which clearly shows that FSO channel is giving its peak performance from 50 to $100 \mathrm{~m}$ range. Figure 7 and 8 shows the Min. $\log$ of BER and Q factor with respect to the FSO channel range and it shows that after $100 \mathrm{~m}$ the BER and $\mathrm{Q}$ factor shows poor performance and hence FSO channel is best suited for range from 50 to $100 \mathrm{~m}$.
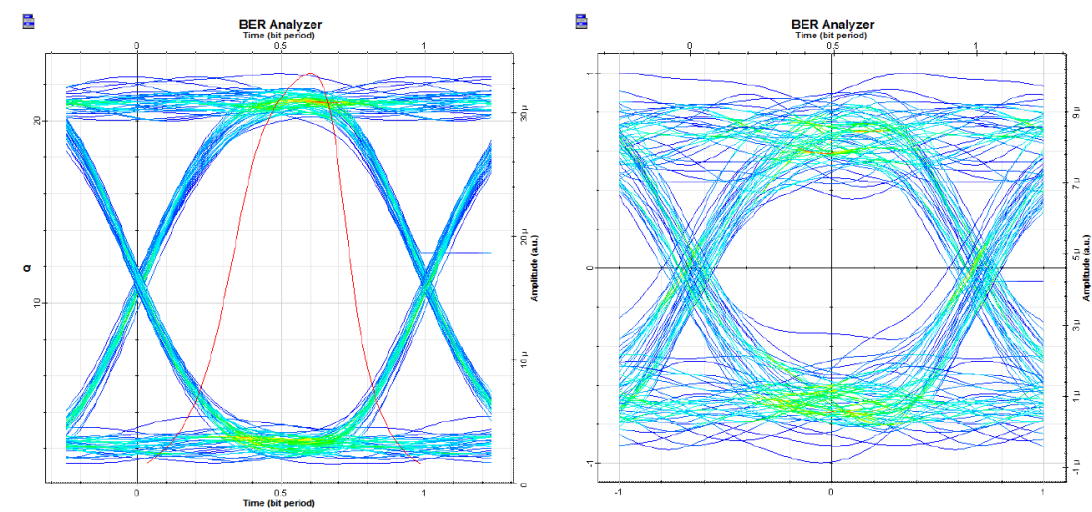

Figure 6. Downstream for Hospital block FSO channel range 50m and 100m.

Table 3. Hospital block BER analyzer values.

\begin{tabular}{|c|c|c|c|}
\hline Range (m) & Max. Q Factor & Min. BER & Min. log of BER \\
\hline 50 & 22.58 & $3.40298 \mathrm{e}-113$ & -112.468 \\
\hline 100 & 6.2209 & $2.46883 \mathrm{e}-010$ & -9.60751 \\
\hline 150 & 2.14274 & 0.0159928 & -1.79608 \\
\hline 200 & 0 & 1 & 0 \\
\hline 250 & 0 & 1 & 0 \\
\hline
\end{tabular}



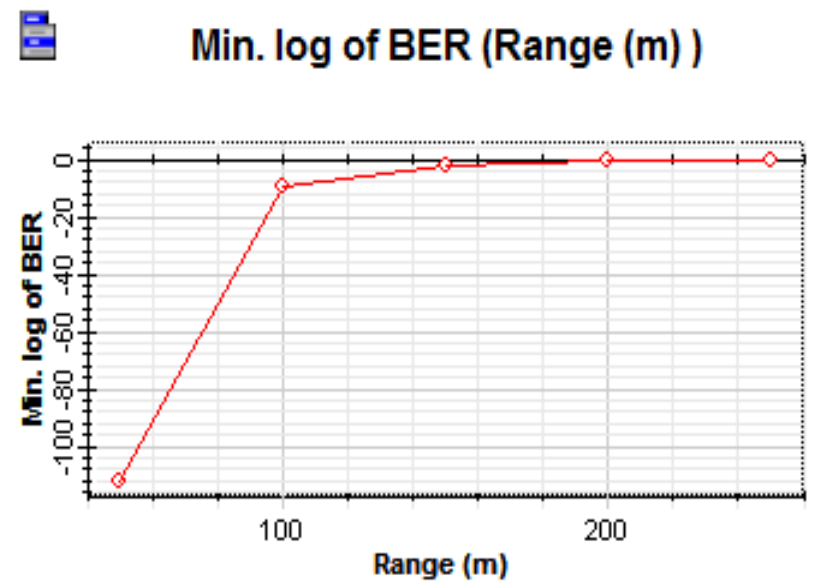

Figure 7. Min. log of BER Vs FSO channel range for hospital block.
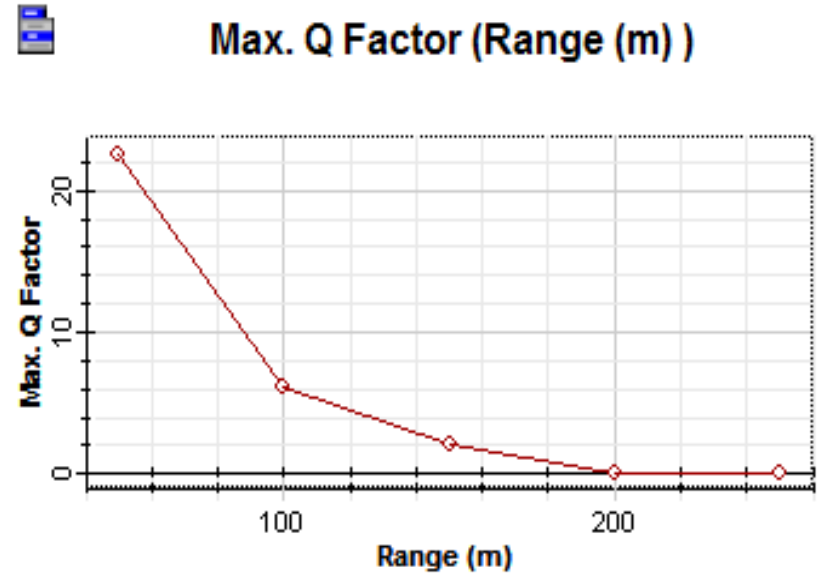

Figure 8. Max. Q Factor Vs FSO channel range for Hospital block.

For the Building block the eye diagrams are shown in Figure 9 and they appear nearly the same as for hospital block hence all other graphs are deliberately not shown for simplicity because both the blocks at the ONU side are providing similar performance for FSO channel range from 50 to $100 \mathrm{~m}$. Table 4 is giving the BER analyzer values for both building sections hence validating this point. 

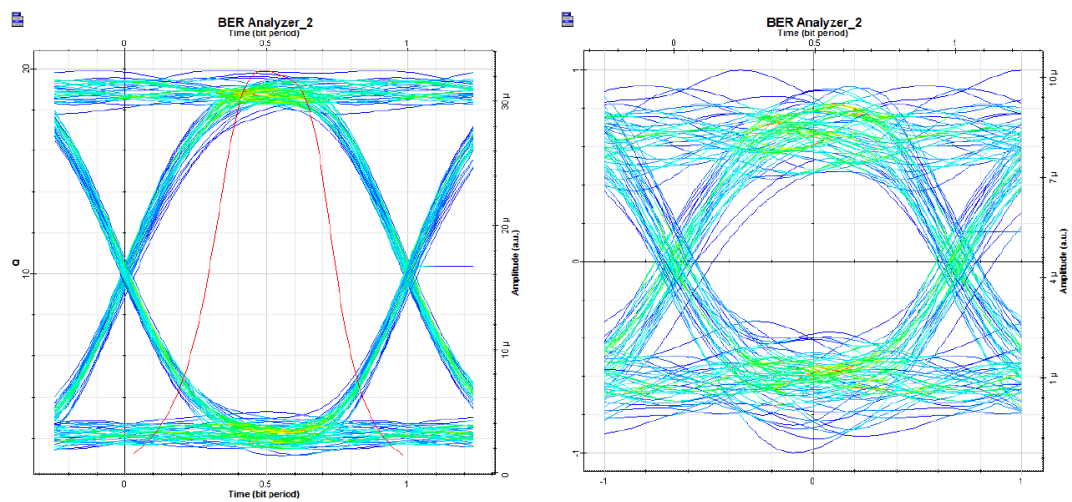

Figure 9. Downstream for Building block FSO channel range $50 \mathrm{~m}$ and $100 \mathrm{~m}$.

Table 4. Building block BER analyzers values.

\begin{tabular}{|c|c|c|c|c|c|c|}
\hline \multirow{2}{*}{$\begin{array}{c}\text { Range }(\mathbf{m}) \text { of } \\
\text { FSO channel }\end{array}$} & \multicolumn{3}{|c|}{ BER analyzer_2 } \\
& $\begin{array}{c}\text { Max. Q } \\
\text { Factor }\end{array}$ & Min. BER & $\begin{array}{c}\text { Min. log of } \\
\text { BER }\end{array}$ & $\begin{array}{c}\text { Max. Q } \\
\text { Factor }\end{array}$ & Min. BER & $\begin{array}{c}\text { Min. log of } \\
\text { BER }\end{array}$ \\
\hline 50 & 19.913 & $1.56954 \mathrm{e}-088$ & -87.8042 & 21.4066 & $5.78105 e-102$ & -101.238 \\
\hline 100 & 5.47108 & $2.2316 e-008$ & -7.65138 & 5.57135 & $1.2635 e-008$ & -7.89842 \\
\hline 150 & 2.39446 & 0.00831056 & -2.08037 & 2.67231 & 0.00376535 & -2.42419 \\
\hline 200 & 0 & 1 & 0 & 0 & 1 & 0 \\
\hline
\end{tabular}

Also, Figure 10 shows the cumulative response of $Q$ factor with respect to the range of the FSO channel used building block. Note that the quality of signal drops from $150 \mathrm{~m}$ to onwards.

\section{鼻 Q Factor Iteration: 5}

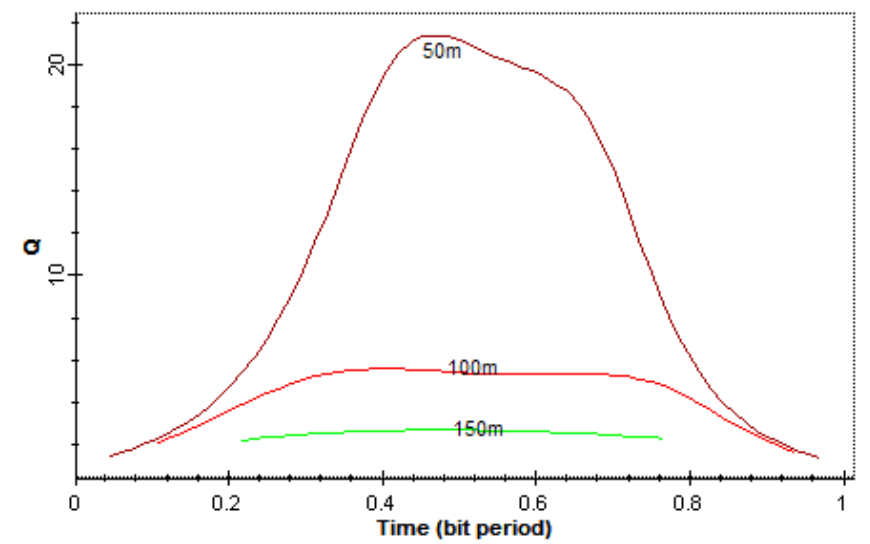

Figure 10. Cumulative response of $Q$ factor in building block w.r.t FSO channel range. 
Finally, Figure 11 shows the min. log of BER vs total power in $\mathrm{dBm}$ comparison of all users.

Bin. log of BER (Total Power (dBm))

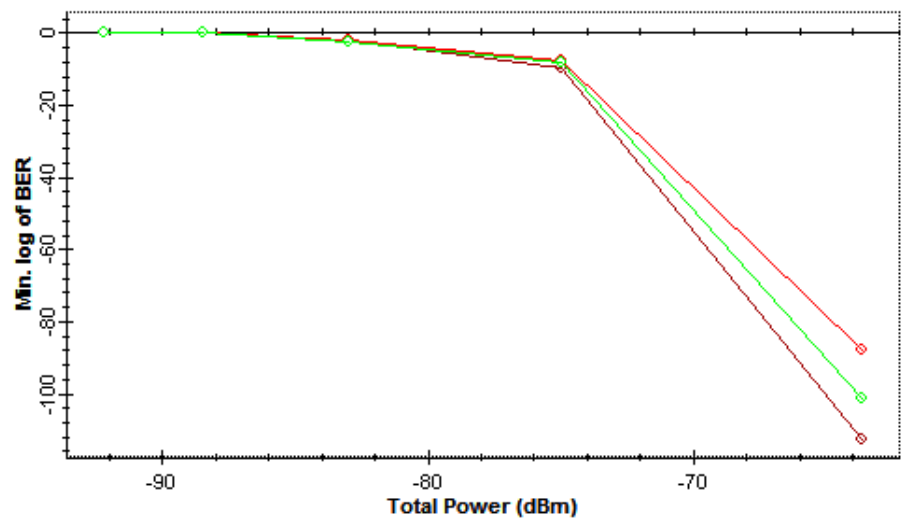

Figure 11. Min. $\log$ of $B E R$ vs Total power for all users.

\subsection{UPSTREAM PERFORMANCE ANALYSIS}

In the case of upstream communication, the OLT becomes receiver as shown in Figure 1. Hence the results are shown in Figure 12 where eye diagrams for upstream FSO channel range $50 \mathrm{~m}$ and $150 \mathrm{~m}$ is shown. It is to note here that in the upstream the eye- opening at the $150 \mathrm{~m}$ range is a little bit better as compared to the transmission in downstream. But the peak performance is still from 50 to $100 \mathrm{~m}$.
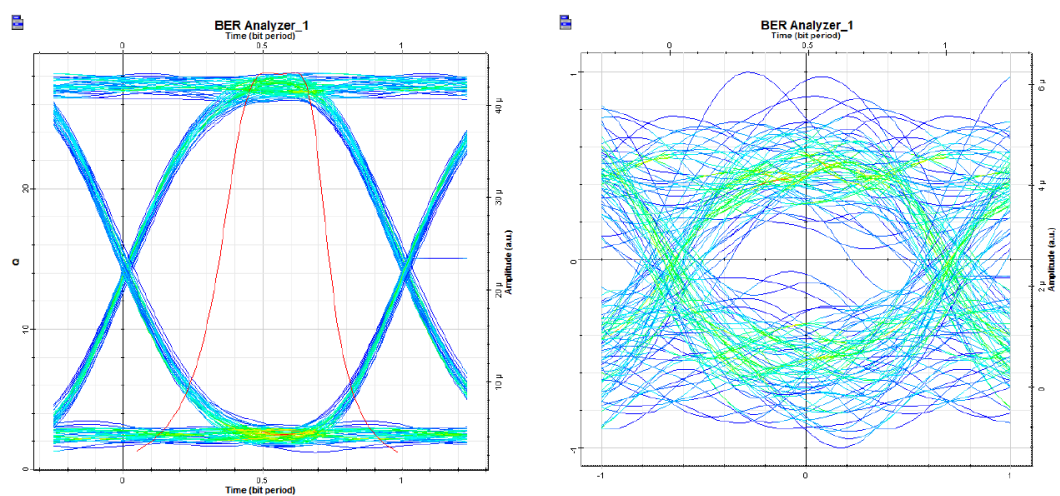

Figure 12. Eye diagrams for upstream FSO channel $50 \mathrm{~m}$ and $150 \mathrm{~m}$. 
Table 5 gives the complete set of BER analyzer values for upstream communication, showing the ideal performance is up to $100 \mathrm{~m}$ range. Figure 13 gives the graph of min log of BER at the OLT side for upstream at different ranges of FSO channel. Note that at $50 \mathrm{~m}$ the BER produces peak performance as at this point the BER achieved is $5.75 \times 10-176$. At $100 \mathrm{~m}$ the BER value is 4.91×10-16 and after that BER degrades significantly.

Table 5. BER analyzer values for upstream.

\begin{tabular}{|c|c|c|c|}
\hline Range (m) & Max. Q Factor & Min. BER & Min. log of BER \\
\hline 50 & 28.2572 & $5.75632 e-176$ & -175.24 \\
\hline 100 & 8.02883 & $4.91682 \mathrm{e}-016$ & -15.3083 \\
\hline 150 & 3.14412 & 0.000830138 & -3.08085 \\
\hline 200 & 0 & 1 & 0 \\
\hline 250 & 0 & 1 & 0 \\
\hline
\end{tabular}

量 Min. BER Iteration: 5

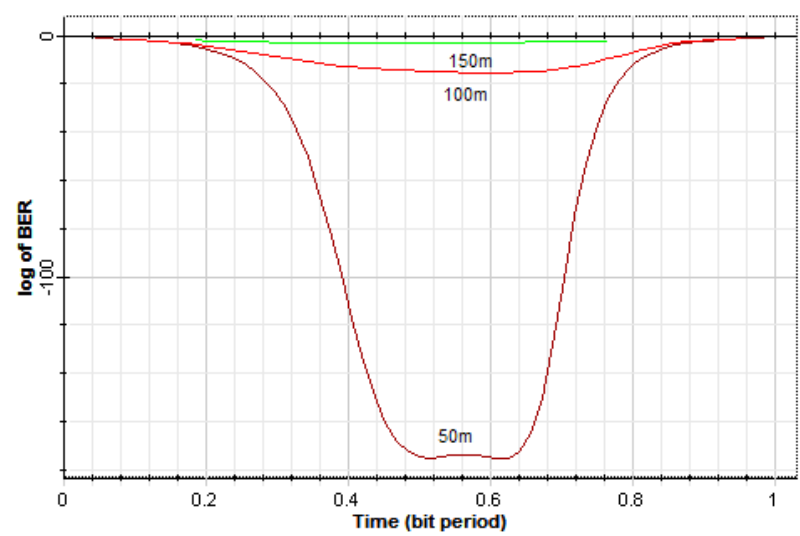

Figure 13. Min. log of BER at the OLT side for upstream at different ranges of FSO channel.

\section{CONCLUSION}

With the above discussion and results it can be concluded here that bidirectional free-space optical channels are providing good quality data transmission in hybrid TDM/WDM GPON system at the range from $50 \mathrm{~m}$ to $100 \mathrm{~m}$. BER of the order of $10^{-16}$ and $10^{-12}$ at a distance of $100 \mathrm{~m}$ for both upstream and downstream is achieved which means it can be practically implemented. But if the range is greater than $100 \mathrm{~m}$ the system performance deteriorates significantly. Therefore careful considerations must be taken while installing the FSO channel. 


\section{ACKNOWLEDGEMENTS}

This work is supported by Mehran University of Engineering and Technology,

Pakistan. 


\section{REFERENCES}

Ahsan M. S., Lee, M. S., Newaz, S. H.\& Asif, S. M. (201 1). Migration to next generation optical access networks using hybrid WDM/TDM-PON. Fournal of Networks, 6(1), pp. 18-25. doi: http://dx.doi.org/10.4304/jnw.6.1.18-25

Elaydi, M. A. (2014). Next Generation Passive Optical Network Stage Two, NG-PON2 (Master's Thesis, The Islamic University, Gaza). Retrieved from https:/ /library.iugaza.edu.ps/thesis/ 114046.pdf

Kaur, A., Kaur, B. \& Singh, K. (2017). Design and performance analysis of bidirectional TWDM-PON employing QAM-OFDM for downstream and re-modulation for upstream. Optik, 134, pp. 287-294. doi: http://dx.doi. org/10.1016/j.ijleo.2017.01.009

Liu, Y., Zhang G. \& Li, Q. (2011). WDM/TDM Hybrid GPON Technology. Symposium on Photonics and Optoelectronics (SOPO), Wuhan, pp. 1-3. doi: http:// dx.doi.org/10.1109/SOPO.2011.5780515

Memon, K. A., Umrani, A. W., Unar, M. A., Shah, W. \& Chowdhry, B. S. (2018). Spectral Amplitude Coding Optical CDMA: Performance Analysis on Free Space Optical Channel. International Fournal of Engineering \& Technology, 7(4.38), pp. 31-33. doi: http://dx.doi.org/10.14419/ijet.v7i4.38.24314

Pla, J. S. A. (2011). Design of Passive Optical Network (Master's Thesis, Universidad Politécnica de Valencia, Spain). Retrieved from https://www. vutbr.cz/www_base/zav_prace_soubor_verejne.php?file_id=42988

Skubic, B, Chen, J., Ahmed, J., Wosinska, L. \& Mukherjee, B. (2009). A comparison of dynamic bandwidth allocation for EPON, GPON, and nextgeneration TDM PON. IEEE Communications Magazine, 47(3), pp. 40-48. doi: http://dx.doi.org/10.1109/MCOM.2009.4804388 